\title{
Drag Reduction Through Distributed Electric Propulsion
}

\author{
Alex M. Stoll*and JoeBen Bevirt ${ }^{\dagger}$ \\ Joby Aviation, Santa Cruz, California, 95060 \\ Mark D. Mooreł William J. Fredericksई and Nicholas K. Borer \\ NASA Langley Research Center, Hampton, Virginia, 23681
}

\begin{abstract}
One promising application of recent advances in electric aircraft propulsion technologies is a blown wing realized through the placement of a number of electric motors driving individual tractor propellers spaced along each wing. This configuration increases the maximum lift coefficient by providing substantially increased dynamic pressure across the wing at low speeds. This allows for a wing sized near the ideal area for maximum range at cruise conditions, imparting the cruise drag and ride quality benefits of this smaller wing size without decreasing takeoff and landing performance. A reference four-seat general aviation aircraft was chosen as an exemplary application case. Idealized momentum theory relations were derived to investigate tradeoffs in various design variables. Navier-Stokes aeropropulsive simulations were performed with various wing and propeller configurations at takeoff and landing conditions to provide insight into the effect of different wing and propeller designs on the realizable effective maximum lift coefficient. Similar analyses were performed at the cruise condition to ensure that drag targets are attainable. Results indicate that this configuration shows great promise to drastically improve the efficiency of small aircraft.
\end{abstract}

\section{Nomenclature}

A disk area of a single propeller

$b_{\text {blown }}$ blown wingspan

$C_{D} \quad$ drag coefficient

$C_{L} \quad$ lift coefficient

$C_{P} \quad$ power coefficient, $P / \rho_{\infty} n^{3} d^{5}$

$C_{T} \quad$ thrust coefficient, $T / \rho_{\infty} n^{2} d^{4}$

$C_{L_{\max }}$ maximum lift coefficient

$c_{l_{\max }}$ maximum section (2D) lift coefficient

d propeller diameter

$M \quad$ figure of merit

$N \quad$ propeller normal force

$n \quad$ propeller angular velocity, rps

$N_{p} \quad$ number of propellers

$N_{T_{\alpha}} \quad$ propeller normal force ratio derivative, $\partial(N / T) / \partial \alpha_{p}$

$P \quad$ shaft power of a single propeller

\footnotetext{
*Aeronautical Engineer, 340 Woodpecker Ridge, AIAA Member.

${ }^{\dagger}$ Founder, 340 Woodpecker Ridge.

${ }^{\ddagger}$ Project Lead, Aerospace Engineer, Aeronautics Systems Analysis Branch, E403, AIAA Senior Member

$\S$ Advanced Concepts, Aerospace Engineer, Aeronautics Systems Analysis Branch, E403, AIAA Member.

ף Aerospace Engineer, Aeronautics Systems Analysis Branch, 1 N. Dryden St. MS 442, AIAA Senior Member.

Copyright (C) 2014 by Joby Aviation, LLC. Published by the American Institute of Aeronautics and Astronautics, Inc. with permission.
} 
$P_{t} \quad$ total shaft power of all propellers

$q_{\infty} \quad$ free-stream dynamic pressure

$T \quad$ thrust of a single propeller

$T_{c} \quad$ thrust coefficient based on free airstream, $T / q_{\infty} A$

$V_{\infty} \quad$ free-stream velocity

Symbols

$\alpha \quad$ aircraft angle of attack

$\alpha_{p} \quad$ propeller disk angle of attack

$\rho_{\infty} \quad$ free-stream mass density of air

$\zeta_{i, x} \quad$ axial induced velocity ratio based on free airstream

$\zeta_{i, z} \quad$ normal induced velocity ratio based on free airstream

\section{Introduction}

Electric propulsion possesses the potential to create a much greater paradigm shift in aircraft design than might be initially apparent, because while directly replacing combustion engines with electric motors does impart benefits of simplicity, reliability, low noise, and low maintenance, far greater benefits may be realized by taking advantage of the unique properties of electric propulsion through configurations that have been impractical or impossible with traditional propulsion systems. This is due to the relatively small size and low weight of electric motors and the ability to scale electric motors without a significant loss of efficiency or specific power. These characteristics provide the freedom to employ a multitude of small electric motors and propellers in strategic locations on the aircraft, resulting in a great increase in flexibility in the design of aircraft configurations. In contrast, traditional propulsion systems typically tightly constrain aircraft designs due to scaling effects and the large size and mass of combustion engines, which normally dictate the use of no more than a small number of engines placed in a small number of practical locations.

One distributed electric propulsion (DEP) configuration that shows great potential is named Leading Edge Asynchronous Propellers Technology (LEAPTech) and features many small propellers distributed spanwise along the wing that blow the wing during takeoff and landing. This increases the dynamic pressure over the wing, facilitating lower stall speeds and/or reduced wing area without the need for structurally complex traditional multi-element high-lift systems. If the stall speed requirements are retained, a significantly smaller wing may be employed, because the wing is typically sized to meet takeoff and landing constraints. This smaller wing can result in a large reduction in cruise drag as well as substantially improved ride quality due to decreased gust sensitivity. ${ }^{1}$

While there are many other active flow control technologies that could similarly be applied to achieve improved takeoff and landing high lift performance without structural complexity, these technologies offer only a single integration benefit at the cost of significant integration penalties. However, DEP offers the potential of additional integration benefits across other disciplines, resulting in greater integration benefits than penalties. Examples of multidisciplinary benefits this specific DEP approach offers include the following capabilities:

- distributed electric propulsors that are optimized for the low speed aerodynamic, propulsive, and acoustic requirements without the complexity of variable pitch

- variable disk loading achieved by toggling the operation of individual propulsors to optimally match propulsive characteristics to the operating flight conditions

- distributed electric propulsors that provide redundant and robust propulsive control which is enhanced instead of degraded at low airspeeds

- cruise optimized aeropropulsive coupling in distributed locations where synergistic wingtip vortex integration benefits can be achieved

\section{Configuration Description}

A configuration was designed at the general aviation scale to enable spiral development which could rapidly achieve full-scale data validation of the highly integrated aerodynamic, propulsive, control, and 
acoustic characteristics. A far more clear understanding of the configuration benefits is achieved by comparing to an exemplary general aviation aircraft such as the Cirrus SR22, which represents the current state of the art for this class of aircraft. Specifications of the two aircraft designs are compared in table 1.

\begin{tabular}{l|ll} 
& Cirrus SR22 & LEAPTech \\
\hline Seating capacity & $4^{2}$ & 4 \\
Gross weight & $3,400 \mathrm{lb}^{2}$ & $3,000 \mathrm{lb}$ \\
Wing area & $145 \mathrm{ft}^{22}$ & $55.1 \mathrm{ft}$ \\
Wingspan & $38.3 \mathrm{ft}^{2}$ & $31.0 \mathrm{ft}$ \\
Aspect ratio & 10.1 & 17.4 \\
Wing loading & $23.5 \mathrm{lb} / \mathrm{ft}^{2}$ & $54.4 \mathrm{lb} / \mathrm{ft}^{2}$ \\
Cruise speed & $211 \mathrm{mph}^{3}$ & $200 \mathrm{mph}$ \\
Cruise $C_{L}(12,000 \mathrm{ft})$ & 0.30 & 0.77
\end{tabular}

Table 1. Comparison of the reference configuration with the Cirrus SR22

In this design, eighteen electric motors are mounted in nacelles regularly spaced spanwise along the wing leading edge and drive propellers that increase the dynamic pressure over the wing during takeoff and landing. The propellers spin at relatively low tip speeds to minimize noise. Propulsion in cruise flight is outside the scope of this analysis, but is intended to be fulfilled by a combination of some of these propellers, separate propellers mounted on the wingtips to take advantage of the wingtip vortex, and/or a separate propeller mounted on the tail boom to take advantage of the fuselage boundary layer. Any of the leading edgemounted propellers not required for cruise propulsion fold flat against the respective nacelles to minimize drag. Design conditions are summarized in table 2. An early conceptualization of this aircraft, using only ten leading edge-mounted propellers, is shown in figure 1.

\begin{tabular}{l|lll} 
& Cruise & Takeoff & Landing \\
\hline Altitude & $12,000 \mathrm{ft}$ & Sea level & Sea level \\
Airspeed & $200 \mathrm{mph}$ & 61 knots & 61 knots \\
Flap angle & $0^{\circ}$ & $10^{\circ}$ & $40^{\circ}$ \\
Total leading-edge propeller shaft power & & $240 \mathrm{hp}$ & $300 \mathrm{hp}$
\end{tabular}

Table 2. Design conditions

The placement of the propellers ahead of the leading edge, compared to locations aft of the wing, was chosen for favorable pitching moment, acoustic, structural complexity, and cruise drag properties, and, importantly, results in a lower degree of uncertainty in the aerodynamic analysis. ${ }^{4}$

\section{Design and Analysis}

\section{A. Theoretical Background}

Idealizing a propeller at angle of attack $\alpha_{p}$ as an actuator disk, the axial induced velocity in the far wake (i.e., far enough downstream that the wake has contracted) is given by momentum theory as

$$
\zeta_{i, x}=\sqrt{\cos ^{2} \alpha_{p}+T_{c}}-\cos \alpha_{p}
$$

where $T_{c}$ is the ratio of disk loading to free-stream dynamic pressure.

If the propeller axis is aligned with the free-stream velocity (i.e., $\alpha_{p}=0$ ), the dynamic pressure in the far wake is then simply $q_{\infty}+T / A$, or $q_{\infty}\left(1+T_{c}\right)$. If $N_{p}$ propellers are distributed adjacently along a total wingspan $b_{\text {blown }}$, each propeller diameter will be $b_{\text {blown }} / N_{p}$. Then, again using momentum theory, the thrust coefficient $T_{c}$ may be related to the total shaft power $P_{t}$ by

$$
\frac{8 N_{p} P_{t} M}{q_{\infty} V_{\infty} \pi b_{\text {blown }}^{2}}=T_{c}\left(1+\sqrt{1+T_{c}}\right)
$$




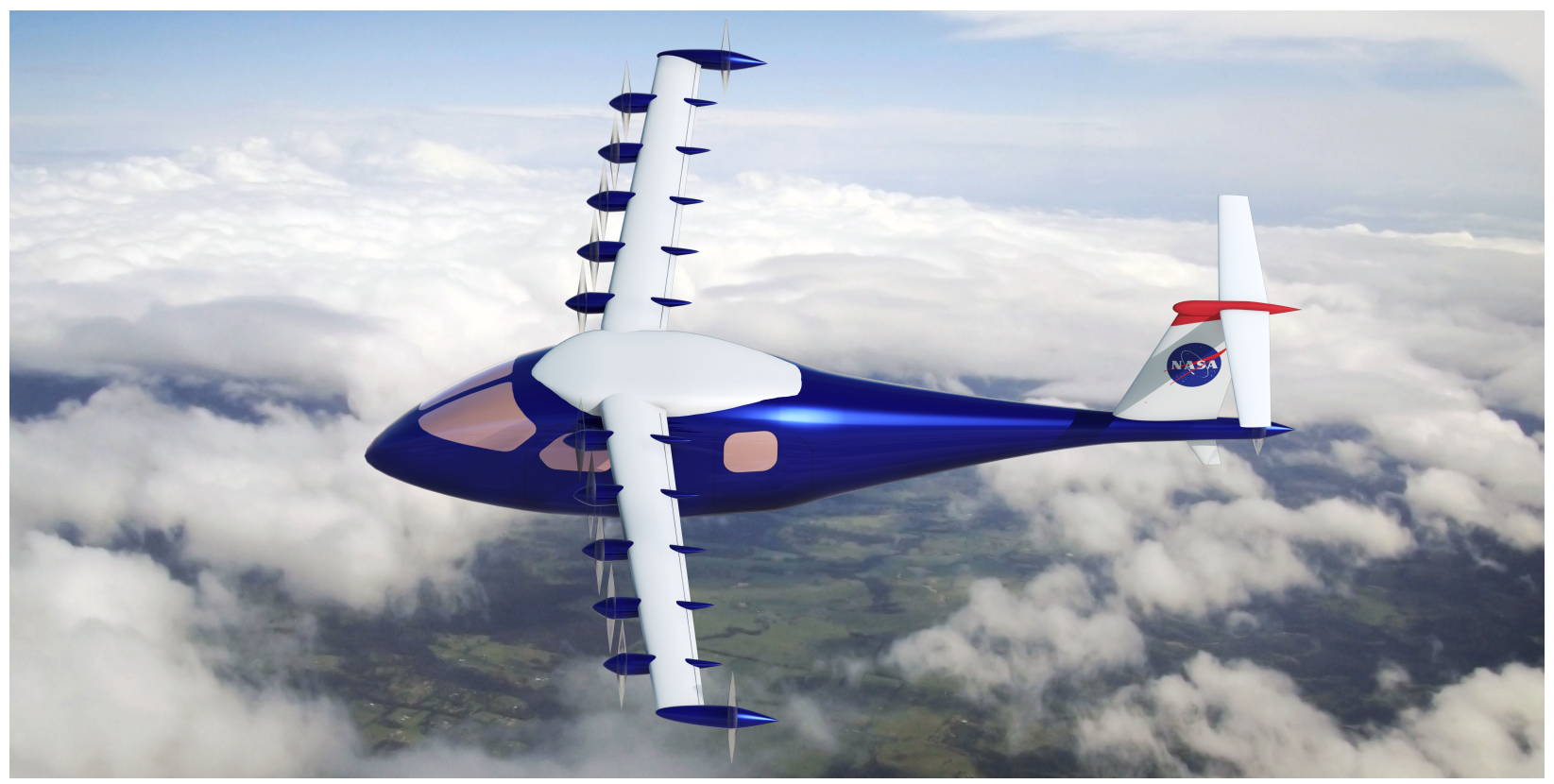

Figure 1. An early conceptualization of the LEAPTech aircraft, with ten leading edge-mounted propellers.

where $M$, the figure of merit, is the ratio of ideal power required (as calculated from momentum theory) to actual power required.

By inspection of equation (2), increasing $N_{p}$ will increase the dynamic pressure over the wing at fixed total power $P_{t}$. However, because the total thrust at fixed $P_{t}$ can be shown to be proportional to $T_{c} / N_{p}$, total thrust will decrease with increasing $N_{p}$. These relations are graphically illustrated in figure 2 .

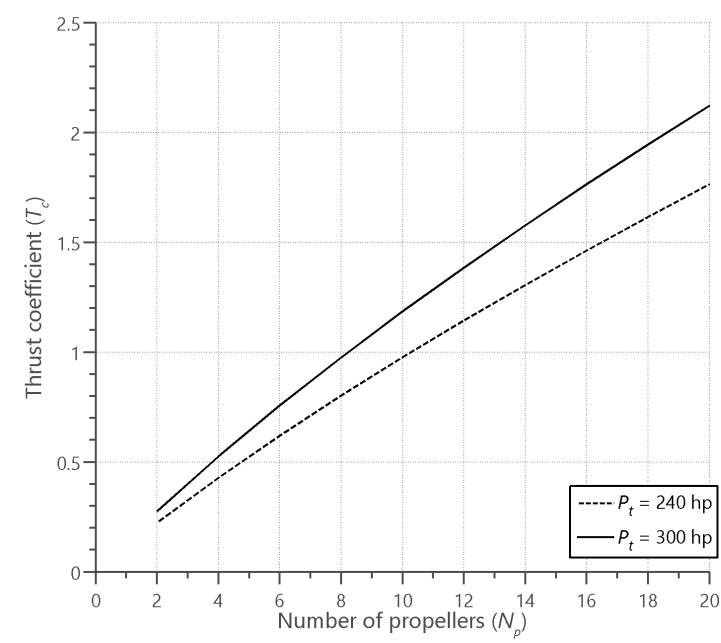

(a) Effect of propeller count on thrust coefficient

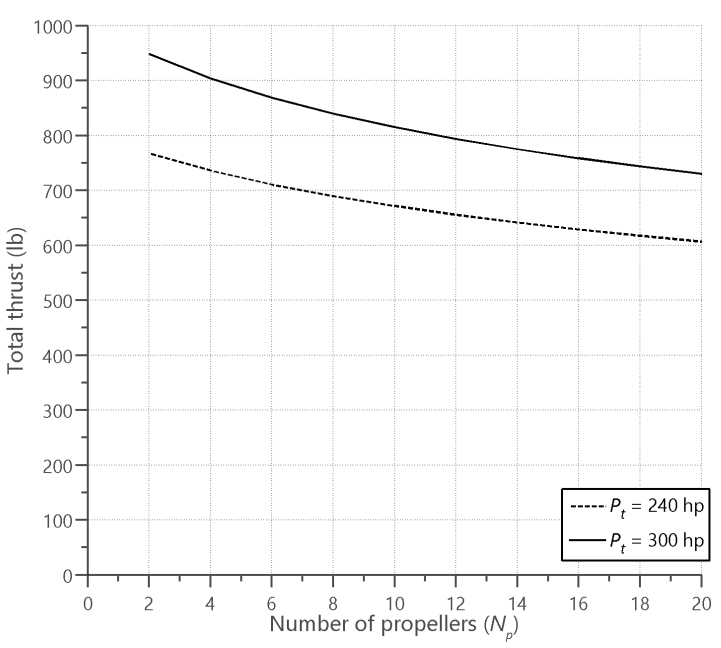

(b) Effect of propeller count on total thrust

Figure 2. Trends for $M=63 \%$ and $b_{\text {blown }}=26.4 \mathrm{ft}$ at the takeoff and landing conditions.

Matters become more interesting when one considers nonzero values for the angle of attack of the propeller $\alpha_{p}$. In this case, the local air velocity encountered by the blown portion of the wing may be idealized as a vector sum of the free-stream velocity and the axial and normal velocities induced by the propeller; therefore, varying propeller parameters will affect local angle of attack as well as local dynamic pressure. For a given value of the propeller normal force $N$, the far wake normal induced velocity may be calculated from momentum theory as 


$$
\zeta_{i, z} \approx \frac{N / q_{\infty} A}{2 \cos \alpha_{p}+\zeta_{i, x}}
$$

To simplify analysis, it can be assumed that

$$
N / q_{\infty} A \approx N_{T_{\alpha}} T_{c} \alpha_{p}
$$

$N_{T_{\alpha}}$ is a function of advance ratio and propeller geometry, and can be estimated using blade element momentum theory (BEMT). Thrust can assumed to be constant with $\alpha_{p}$.

However, the increased dynamic pressures do not directly translate to a corresponding increase in $C_{L}$ due to several factors. In addition to the normal and axial induced velocities, swirl is imparted into the slipstream; this increases the angle attack on the wing on one side of the propeller axis and decreases it on the other. For this reason, a wing using an airfoil with gentle stall characteristics may be able to achieve a higher total blown $C_{L}$ than one employing an airfoil with a higher $C_{L_{\max }}$ but which stalls more abruptly. This swirl may be largely neutralized by using contra-rotating propellers, at the cost of complexity and a higher noise signature. Additionally, in contrast with the simple actuator disk model, the radial distribution of the axial induced velocity in a properly-designed propeller increases from the root to the tip, with the result that the dynamic pressure increase across the blown wing section is not uniform. Furthermore, wake contraction slightly reduces the effective blown span of the affected wing sections, with greater contraction corresponding to larger values of $T_{c}$.

\section{B. Computational Fluid Dynamics (CFD) Analyses}

To achieve high confidence in the realizable aerodynamics of this configuration, extensive CFD analyses were performed. These were accomplished using the commercial code STAR-CCM+ for both mesh generation and CFD solutions. Navier-Stokes simulations were run using the SST (Menter) $k$ - $\omega$ turbulence model and the $\gamma-\operatorname{Re}_{\theta}$ transition model on unstructured meshes.

\section{Wing Design}

The chief design objective was to produce adequate lift at the landing conditions without significant cruise drag compromises. Analysis of the wing and propeller configuration was chiefly performed using steady CFD with propellers modeled as actuator disks. The actuator disk model employed prescribes radial force distributions according to the Goldstein optimum, but assumes uniform tangential force distributions and therefore does not incorporate normal forces and induced velocities. However, these effects are minor at the relevant angles of attack.

The wingspan was fixed, and for simplicity and cost considerations, all propellers and motors are identical (aside from employing left- and right-handed propeller variants). The wing taper and rate of twist are constant across the exposed span for simplicity of design and analysis. $4^{\circ}$ of washout was chosen to provide benign stalling characteristics, and the taper ratio of 0.50 was chosen from structural considerations. The wing loading was chosen to be close to the value for maximum range at the specified cruise conditions while remaining high for favorable ride quality. The wing sweep angle of $10^{\circ}$ at the leading edge was chosen for structural considerations, as well as to allow the propeller disks to be distributed adjacently spanwise by staggering them chordwise.

The number of propellers $N_{p}$ was chosen to maximize the blowing effect without resorting to the complexity of an excessively large number. Additionally, Reynolds number effects on the propeller blades limit the benefits of increasing $N_{p}$ too much further. CFD analysis on various configurations indicated that distributing the propellers across the entire wingspan (rather than, e.g., concentrating the propellers on the inner portion of the wing) provides the greatest benefit.

Initially, a variable-incidence wing (similar to the system on the Vought F-8 Crusader) was considered, in which the wing (along with the leading edge propellers) would increase its incidence in takeoff and landing relative to its cruise incidence by up to $30^{\circ}$. This provides the added benefit of a significant vertical component of propeller thrust during landing and takeoff, increasing the effective $C_{L_{\max }}$ and reducing the aerodynamic demands on the wing, which would then require only a plain flap. However, this configuration is also dangerously vulnerable to a drastic and asymmetric loss of lift in the event of a motor or propeller failure, since, at high incidence angles, the effective angle of attack is significantly reduced by the propeller 
downwash. Therefore, it was decided to employ a fixed-incidence wing using 30\% chord full-span Fowler flaps, with roll control achieved through spoilers. The airfoil is based off of the GA(W)-1 17\% thick airfoil designed for the ATLIT program, ${ }^{5}$ although the flap airfoil was modified using MSES, a 2D multi-element airfoil design code, to improve performance at the design takeoff and landing conditions. The predicted 2D $c_{l_{\max }}$ of the resultant geometry is about 3.4.

Simple 2D calculations using BEMT thrust values and lift curves derived from 2D airfoil analyses with inflow conditions determined from momentum theory calculations of the propeller downwash show low sensitivity of effective $C_{L_{\max }}$ to the propeller incidence angle relative to the wing chord line; therefore, all of the propeller axes were chosen to align with the free-stream velocity at cruise to minimize cruise drag (although a more thorough analysis could determine that small deviations from these angles will result in a further cruise drag reduction).

Contra-rotating propellers were considered as a means to raise $C_{L_{\max }}$ by reducing swirl in the propeller downwash; however, CFD results indicated that the design goals could be met without resorting to the extra complexity and increased noise signature of a contra-rotating configuration.

CFD results of the resulting wing design (as shown in figure 4) indicate maximum lift of over $3,600 \mathrm{lb}$ (corresponding to a $C_{L_{\max }}$ of over 5.2) and a relatively flat $C_{L^{-}} \alpha$ curve due to the influence of the propeller downwash on the effective angle of attack experienced by the wing. This is shown in figure 3, where "Effective $C_{L}$ " includes the vertical component of the propeller thrust. The flattening out of the curve at higher angles of attack is due to the unblown, unflapped center section stalling.

A similar CFD analysis, although without propulsion effects, was performed on the entire aircraft at the cruise condition, resulting in an $L / D$ of 22.4. Pressure coefficient contours from this analysis are shown in figure 5. An assumption of an increment in parasitic drag of $15 \%$ to account for excrescence drag and drag due to the folded propellers still results in an $L / D$ of over 20 , which compares favorably to the SR22's $L / D$ of 11 at $200 \mathrm{mph}$ (as calculated from the SR22 drag polar estimate of

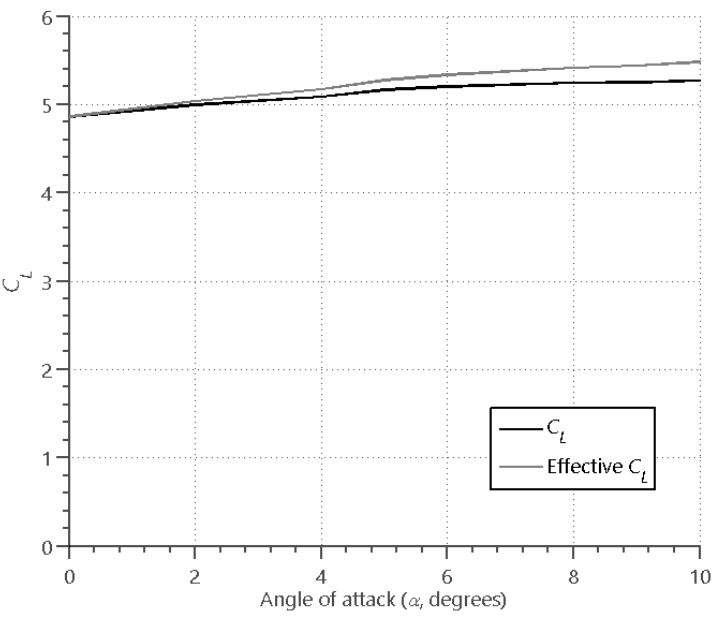

Figure 3. Lift curve of the LEAPTech wing at landing conditions from steady CFD utilizing actuator disks. $C_{D}=0.0288-0.00850 C_{L}+0.0437 C_{L}^{2}$, which is an updated and calibrated formulation of the SR22 polar estimated by Patterson et $\mathrm{al}^{6}$ ).

Further efficiency gains relative to the SR22 may be realized with the application of wingtip-mounted propellers and a tail-mounted boundary layer-ingesting propeller, as described previously.

\section{Propeller Design}

The propellers were designed to maximize thrust at the takeoff conditions at a tip speed of $450 \mathrm{ft} / \mathrm{s}$ (which is relatively low, to minimize noise relative to conventional higher-tip speed designs), while remaining unstalled at static conditions (also to minimize noise). The diameter, determined geometrically from the exposed wingspan and number of propellers, is 1.465 feet. These design requirements were met by first designing an optimum propeller at these conditions with a BEMT design code and then employing optimization software with a BEMT analysis code to maximize thrust at these conditions while ensuring that every blade section remains unstalled at static conditions. Steady CFD with a rotating reference frame was then run on an isolated propeller at both conditions to provide higher-fidelity performance analyses (see figure 6). A prototype propeller was then fabricated with a stereo laser sintering process using a glass-filled polyamide powder and tested both statically and at 61 knots to validate the analysis (see figure 7); the results are given in table 3. 


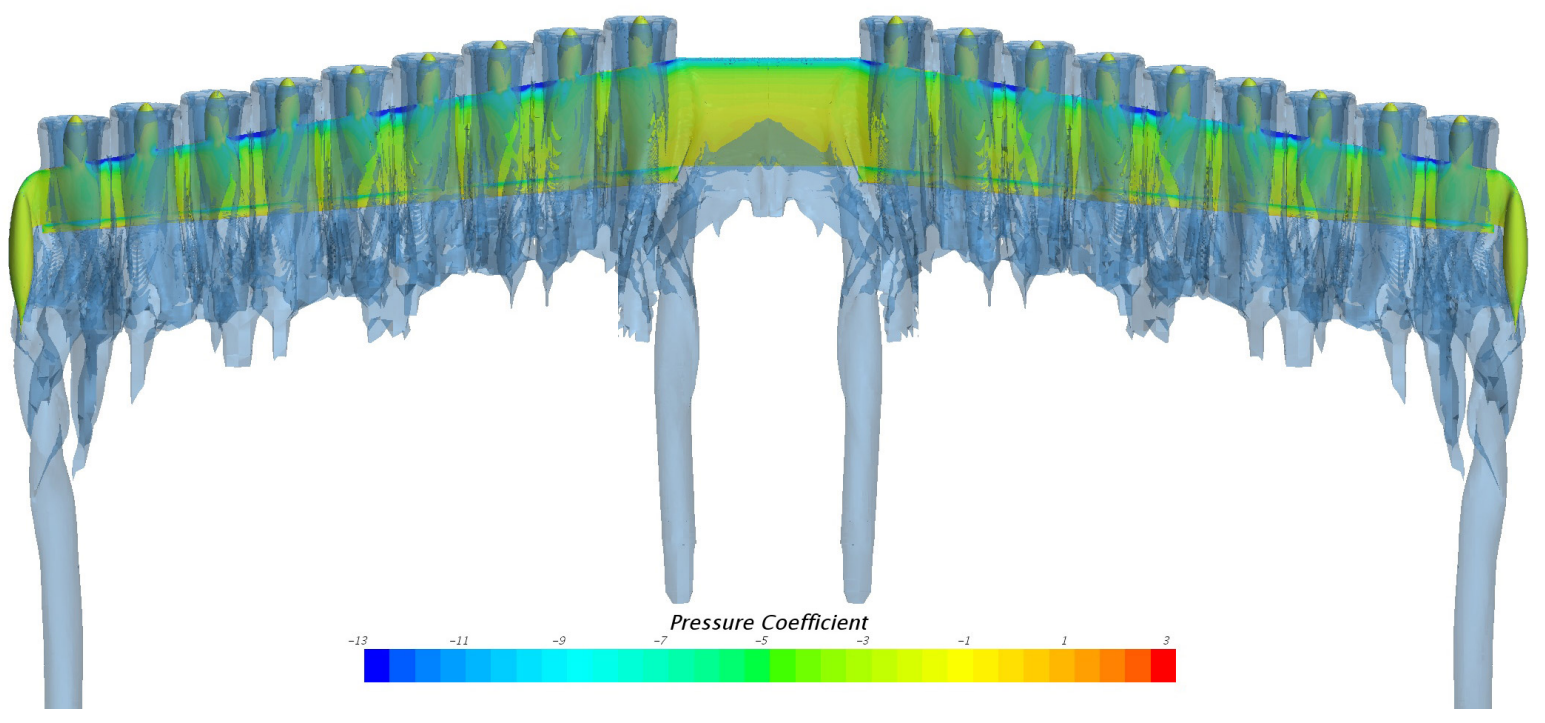

Figure 4. CFD results modeling propellers as actuator disks showing pressure coefficient contours with vorticity isosurfaces at landing conditions and $C_{L}=5.24$.

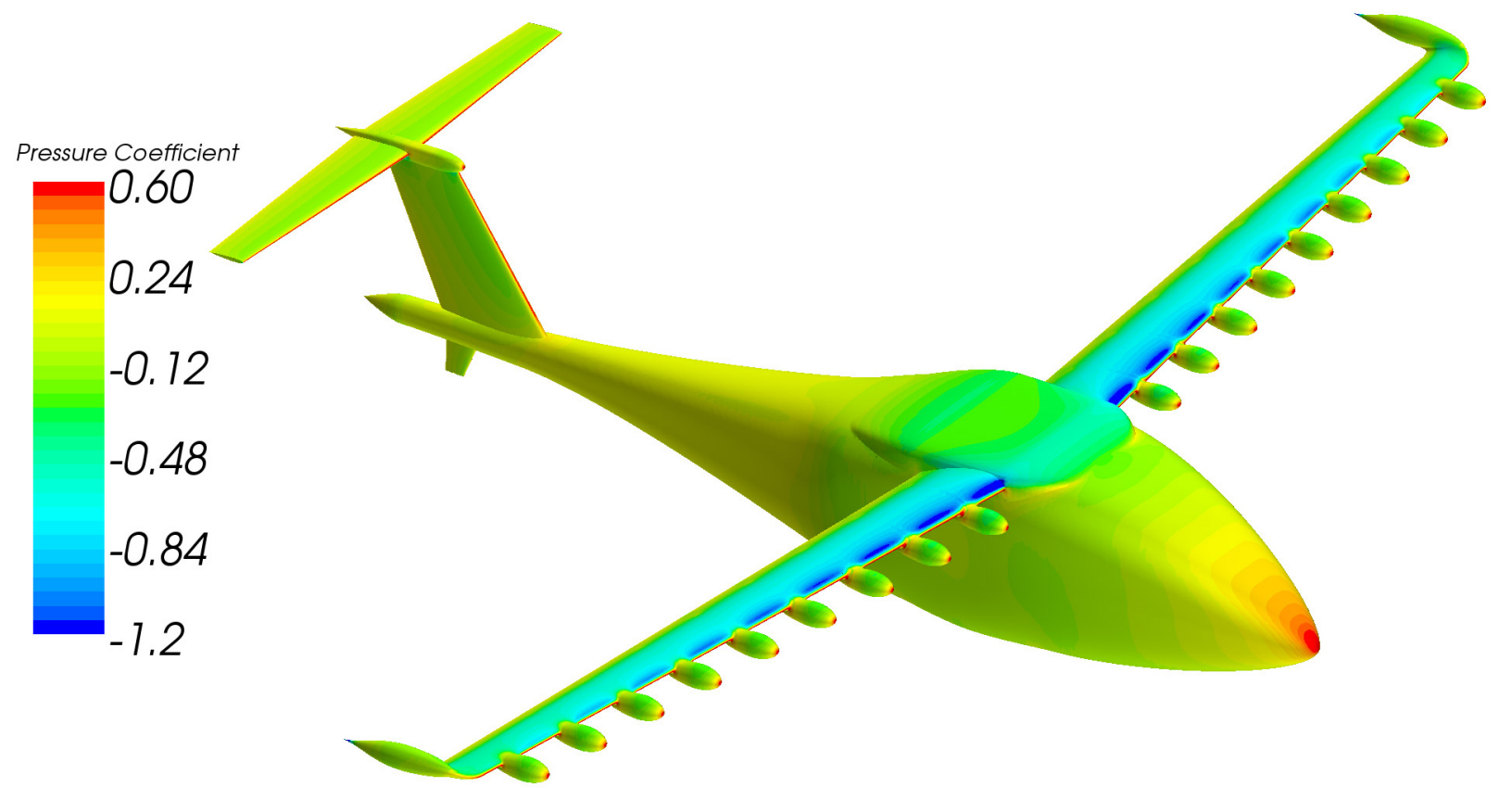

Figure 5. Pressure coefficient contours from CFD analysis at the cruise condition. 


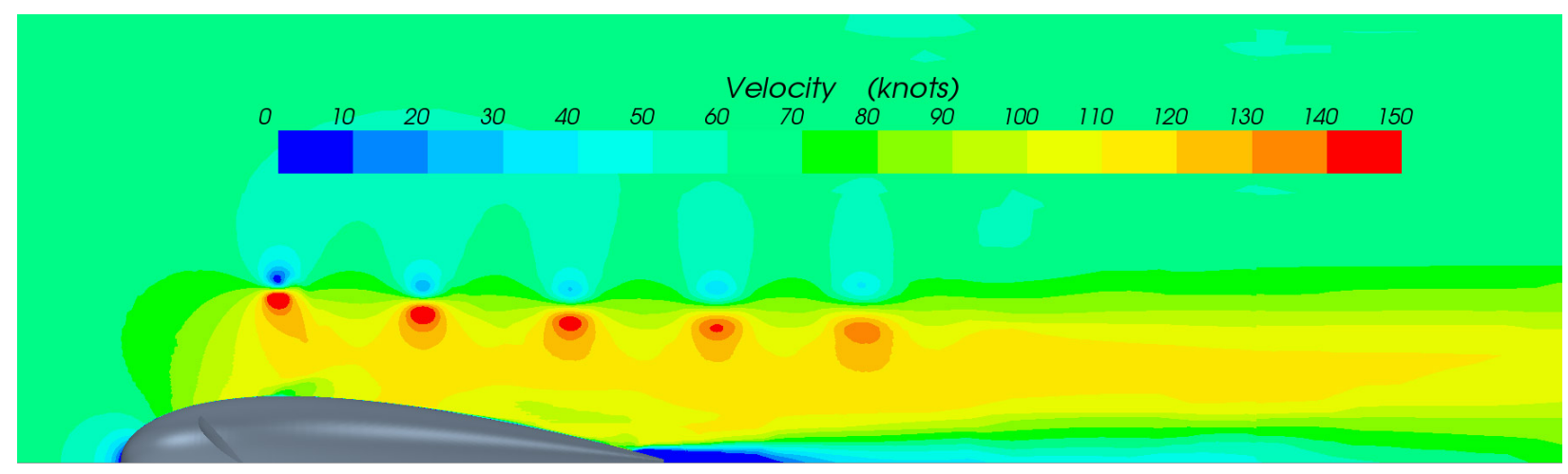

Figure 6. Axial velocity profile from CFD analysis of an isolated propeller at takeoff conditions and $450 \mathrm{ft} / \mathrm{s}$ tip speed.

\begin{tabular}{l|ll} 
& CFD & Experiment \\
\hline$V_{\infty}$ & $61 \mathrm{kts}$ & $61 \mathrm{kts}$ \\
Tip speed & $480 \mathrm{ft} / \mathrm{s}$ & $476 \mathrm{ft} / \mathrm{s}$ \\
$C_{T}$ & 0.354 & 0.352 \\
$C_{P}$ & 0.520 & 0.478 \\
$T_{c}$ & 1.98 & 1.90 \\
$M$ & $62.5 \%$ & $68.5 \%$
\end{tabular}

Table 3. Comparison of analytical and experimental propeller performance. Thrust figures are corrected for nacelle and (in the case of the experimental results) test stand drag.

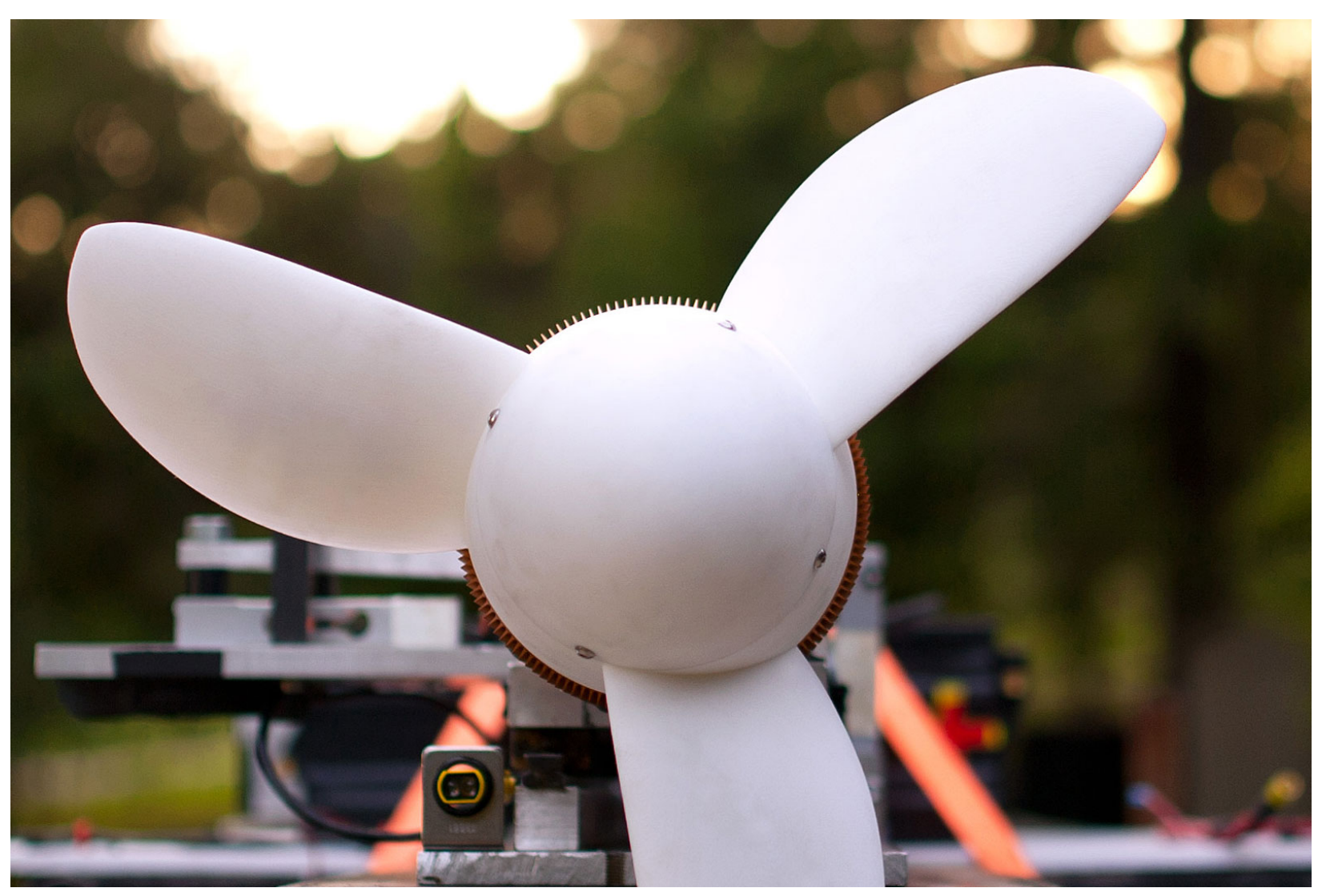

Figure 7. The prototype propeller on the test stand. 


\section{Conclusion}

A series of design iterations on the LEAPTech concept have converged on a distributed electric propulsion aircraft design that, through CFD simulations, shows great promise to deliver unprecedented efficiency and noise signatures in small aircraft without structurally complex traditional multi-element high-lift systems. Aside from the four-seat $200 \mathrm{mph}$ reference design, this configuration could provide significant efficiency gains in higher-speed aircraft, where the high wing loading could provide an even greater advantage, as well as larger aircraft. Upcoming full-scale ground tests of this configuration at landing conditions aim to validate these analytical results and pave the way for flight experiments.

\section{Acknowledgments}

The authors would like to thank Joby Aviation, NASA, and Mark D. Moore for their support and mentorship through the course of this project. This research was funded by NASA Langley Research Center in support of its efforts to pursue understanding of the opportunities provided through highly coupled multidisciplinary integration of distributed electric propulsion. This research involved a close collaboration across NASA Langley, Armstrong, and Ames with participation from a broad group of researchers. The authors would like to extend appreciation to William Milholen, who provided detailed flap MSES analysis, as well as Sean Clarke, Starr Ginn, Lohan Yin, and Bob Curry, all of whom provided valuable insight.

\section{References}

\footnotetext{
${ }^{1}$ Kohlman, D. L., "Flight Test Results for an Advanced Technology Light Airplane," Journal of Aircraft, Vol. 16, No. 4, April 1979, pp. 250-255.

${ }^{2}$ Cirrus Aircraft, 4515 Taylor Circle, Duluth, MN 55811, Airplane Information Manual for the Cirrus Design SR22, Sept. 2011.

3 "Cirrus Aircraft," http://cirrusaircraft.com/sr22/, May 2014.

${ }^{4}$ Moore, M. D. and Fredericks, W. J., "Misconceptions of Electric Aircraft and their Emerging Aviation Markets," AIAA SciTech, American Institute of Aeronautics and Astronautics, Jan. 2014.

${ }^{5}$ Holmes, B. J., "Flight Evaluation of an Advanced Technology Light Twin-Engine Airplane (ATLIT)," NASA CR-2832, July 1977.

${ }^{6}$ Patterson, M. D., German, B. J., and Moore, M. D., "Performance Analysis and Design of On-Demand Electric Aircraft Concepts," Aviation Technology, Integration, and Operations (ATIO) Conferences, American Institute of Aeronautics and Astronautics, Sept. 2012.
} 